\title{
Construção e validação de instrumento para prática interventiva na adoção ${ }^{1}$
}

\author{
Katia Cristina Bandeira Dugnani \\ Susi Lippi Marques ${ }^{2}$ \\ Universidade Federal de São Carlos, São Carlos-SP, Brasil
}

Resumo: Os recursos humanos envolvidos na efetivação da adoção, em especial a tardia, carecem de auxílio que pode provir de resultados de pesquisas que busquem identificar as reais necessidades de todos os atores envolvidos no processo. O presente estudo objetivou construir um instrumento para obtenção de informações sistematizadas para serem posteriormente utilizadas em programa de orientação com pais adotantes tardios. Foi elaborado um formulário, e seus itens foram submetidos à análise teórica (análise de conteúdo e semântica). A análise dos dados revelou sua adequação e congruência frente às exigências psicométricas. Concluiu-se que o instrumento elaborado poderá contribuir, enquanto ferramenta técnica, na promoção da adoção tardia, uma vez que em seus resultados ecoam as vozes dos atores envolvidos neste processo.

Palavras-chave: criança, psicometria, família.

\section{Construction and validation of an instrument for intervening practices in adoption}

\begin{abstract}
The human resources involved in an adoption, particularly late adoptions, demand support originating from research designed to identify the real needs of all actors involved in the process. This study focused on the construction of an instrument to obtain systematized information to be used in adoption orientation programs directed to foster parents of lateadopted children. An instrument was developed and its items were submitted to theoretical analysis (semantic and content evaluation). Data analysis revealed the instrument's adequacy and consistency in relation to psychometric requirements. The conclusion is that the developed instrument, a technical tool, can contribute to late adoptions since the information it collects reflects the voices of the actors involved in the process.
\end{abstract}

Keywords: child, psychometrics, family.

\section{Construcción y validación de instrumento para práctica de intervención en la adopción}

\begin{abstract}
Resumen: A los recursos humanos implicados en efectuar la adopción, especialmente tardía, les falta ayuda, que pueden provenir de resultados de investigaciones que intentan identificar las necesidades reales de todos los involucrados en el proceso. Así, el objetivo de este estudio fue construir un instrumento para la obtención sistemática de información para su uso posterior en el programa de orientación con padres adoptantes tardíos. Fue elaborado un formulario y sus ítem fueron sometidos al análisis teórico (análisis de contenido y semántico) El análisis de los datos reveló su adecuación y coherencia a las exigencias psicométricas. Se concluyó que el instrumento elaborado podrá contribuir, como herramienta técnica, para promover la adopción tardía, ya que sus resultados resuenan las voces de los actores involucrados en este proceso.
\end{abstract}

Palabras clave: niño, psicometría, família.

A palavra adoção deriva do latim adoptione e significa a aceitação legal de um indivíduo como filho. Adoção é tornar filho pela lei e afeto a criança que não teve a proteção devida por àqueles que a conceberam (Freire, 2001). É realizada através de um ato jurídico cuja finalidade é a criação de um vínculo de filiação e inserção de uma criança na família,

\footnotetext{
${ }^{1}$ Este texto foi revisado seguindo o Acordo Ortográfico da Língua Portuguesa (1990), em vigor a partir de $1^{\circ}$ de janeiro de 2009. Esta pesquisa obteve apoio do CNPq e CAPES e representa uma parte da dissertação de mestrado da primeira autora. As autoras agradecem a colaboração das famílias que generosamente participaram deste estudo.

${ }^{2}$ Endereço para correspondência:

Susi Lippi Marques Oliveira. Universidade Federal de São Carlos. Centro de Educação e Ciências Humanas. Departamento de Psicologia. Rodovia Washington Luís (SP-310), Km 235. CEP 13.565-905. São Carlos-SP, Brasil.E-mail:susilmo@ufscar.br
}

sendo este parentesco gerado sem consanguinidade e afinidade (L. Schettini, 2006; Souza, 2003).

A Lei No. 8.069 de 13 de julho de 1990 do Estatuto da Criança e do Adolescente (ECA) em seu capítulo II versa sobre o direito à Convivência Familiar e Comunitária, concebendo ao filho adotivo os direitos iguais ao do filho biológico. Ao ser escolhida e acolhida pela família adotante, a criança adquire todos os direitos e deveres de filho.

Conforme apontado por Vargas (2006), a adoção só se inicia quando há o amor e afeto em todos os sentidos. Mais do que a realização de um desejo é, acima de tudo, um dever e um ato de cidadania (Kossobudzki, 1999). No entanto, considera-se que a criança chega à nova família por um caminho não usual (Levinzon, 2004), sendo esta uma maneira incomum de se ter filhos (L. Schettini, 2006), onde o parentesco é uma relação legal e não através de um relacionamento biológico (Miall, 1996). 
Como o processo da adoção pode ser lento, em decorrência da destituição do poder familiar, a criança permanece institucionalizada ou em casa de famílias substitutas (estágio de convivência), aguardando a finalização a favor ou não da adoção. Esta espera pode levar anos, ficando cada vez mais longínquo o sonho de estas crianças ganharem um novo lar e abandonarem por definitivo as instituições, encontrando uma família que queira adotá-las.

A adoção de crianças acima de 2 anos, denominada adoção tardia, de acordo com Vargas $(1998,2006)$ apresenta características especiais, sendo mais difícil de ser concretizada quando comparada às efetivadas com crianças menores. Quanto mais tardia a adoção, mais vivas serão as lembranças do passado, sendo maior a probabilidade de a criança apresentar desilusões e frustrações devido ao abandono (Andrei, 1999).

Pesquisas nacionais de Beffa e Pocay (1999), Camargo (2005, 2006), Cassin (2000), Maldonado (1995), S. S. M. Schettini (2007), Vargas (1998) e Weber (1999, 2001) apontam a preferência brasileira na adoção de crianças recémnascidas, com cor de pele igual à da família adotante e de preferência do sexo feminino (Cassin, 2000; Paiva, 2004; L. Schettini, 1998; S. S. M. Schettini, 2007), pois as mulheres são vistas como mais dóceis, apresentando melhor adaptação aos novos ambientes. De acordo com Hamad (2002), os postulantes à adoção desejam uma menina, pois é mais fácil a criação, em relação aos meninos.

Essas pesquisas também ressaltam o receio quanto à realização de adoções tardias, embasadas no temor que muitos pais apresentam perante algumas atitudes das crianças (não atendimento às regras, agressividade, etc.) sendo estas contrárias ao que os pais imaginavam ser. Estes sentimentos atribuídos às crianças, conforme evidenciado por Costa (2005), estariam relacionados às representações mentais de maternidade e paternidade valorizando, em princípio, o vínculo constituído com um filho biológico.

É notável a pequena produção de pesquisas envolvendo a adoção de crianças no Brasil, sendo que a maior parte dos estudos na área é oriunda de outros países, como por exemplo, dos Estados Unidos (Bird, Peterson, \& Miller, 2002; Levy-Shiff, 2001) cujos autores buscam estabelecer comparações entre grupo de crianças adotadas e grupo de crianças não adotadas, portanto, focam o adotado e não aquele que adota (Ebrahim, 1999).

Apesar do avanço científico na área temática da adoção, há carência de publicações sobre a adoção tardia. A maioria das publicações brasileiras que aborda esta temática descrevem quadros clínicos e psiquiátricos, associando adoção a problemas e fracassos (Weber, 1999). Especificamente a questão da adoção tardia é pouco investigada, podendo ser este um possível reflexo do preconceito que a sociedade mantém sobre o assunto (Mariano \& Rosseti-Ferreira, 2008; Vargas, 1998).

Freire (2001), ao ressaltar aspectos da nova cultura da adoção a ser implantada no país, aponta para o fato de que esta se baseia na procura de uma família para a criança e não em uma criança que atenda às necessidades e aos desejos da família. Essa nova cultura busca incentivar adoções tardias de grupos de irmãos, de crianças com necessidades especiais, portadoras de HIV e também de adoções inter-raciais (Freire, 2001; Vargas, 1998). Para tanto, no caso da adoção tardia em particular, os pais adotivos devem estar preparados quanto aos possíveis receios que poderão emergir e, também, à certa hostilidade por parte da criança. Por medo de ser novamente abandonada, a criança pode demonstrar sentimentos contrários aos seus desejos, como uma forma de evitar o apego. $\mathrm{Na}$ maioria dos casos de adoção, houve anteriormente uma situação de abandono, separação ou interrupção de algum vínculo (Paiva, 2004). Os pais adotivos devem ser orientados quanto às possíveis reações destas crianças para que estas atitudes não sejam consideradas como rejeição e estes acabem decidindo antecipadamente pela devolução (Andrei, 1999).

A devolução de crianças é apontada por Coakley e Berrick (2008) como um rompimento, uma falha na colocação da criança adotiva. Ainda segundo os autores, apesar das pesquisas não evidenciarem alterações nas taxas de rompimento de adoção, o considerável aumento nos cuidados e serviços de proteção às crianças adotivas possivelmente decorre do índice elevado de crianças e famílias afetadas por esta falha no relacionamento. As causas que levam os pais a devolverem as crianças, seja no período de guarda, no período de convivência ou na adoção efetivada, necessitam ser estudadas para que se tenha uma compreensão a respeito das devoluções de crianças (Viana, 2000).

Dessa maneira, evidencia-se a complexidade da temática, em decorrência de situações subjetivas, tornando-se possível a associação do rompimento com o perfil das crianças "não adotáveis" no contexto social brasileiro, sendo estas (crianças) com idade superior a 2 anos, mulatas ou negras. Parte delas, por não serem adotadas no país de origem, acaba encontrando um lar estrangeiro por meio da adoção internacional (Weber, 2001).

$\mathrm{Na}$ construção de uma cultura de adoção, as dúvidas e receios desencadeados pelos pais ao longo do processo devem ser atenuados, evitando-se, principalmente, a devolução de crianças à instituição. Para atenuar o problema das devoluções, profissionais que atuam em fóruns poderiam intervir no processo por meio de orientações e acompanhamentos. Um fator preponderante para esses profissionais e para os atuantes nos grupos de apoio à adoção é o acesso às informações fidedignas sobre as principais dificuldades, dúvidas e temores dos pais que almejam a adoção, sobretudo a adoção tardia e os motivos que os levam a devolverem crianças.

Partindo desse pressuposto e pela constatação da inexistência de recursos técnicos (instrumental) específicos para abordar questões relativas ao processo de adaptação familiar na adoção tardia, o presente estudo objetivou propor a construção de um instrumento capaz de obter informações válidas e sistematizadas (ponto de vista científico), buscando compreender, através das vozes dos pais adotivos, suas vivências e estratégias para resolução de conflitos e problemas ao longo do processo de adoção. Na prática, poderá ser utilizado 
pelos profissionais diretamente envolvidos nos processos de adoção na busca de informações mais claras e circunstanciadas sobre o convívio familiar e adaptação da criança ao novo ambiente. Esses elementos informativos propiciarão orientações mais eficazes e um acompanhamento preventivo por parte do corpo técnico do fórum. A construção do instrumento foi baseada em leituras de textos e pesquisas realizadas anteriormente na área da adoção tardia (Ebrahim, 1999; Morelli, 2005; Vargas, 1998; Viana, 2000; Weber, 2001, 2003).

\section{Método}

\section{Participantes e local}

Ao longo da construção e aferição do instrumento, a amostra do presente estudo foi composta por 23 colaboradores que foram divididos de acordo com a finalidade para qual foram recrutados. Para a realização da análise de conteúdo, participaram dez juízes peritos na área de adoção, sendo nove na análise da versão preliminar do instrumento e um na análise da versão reestruturada; a análise semântica contou com 11 colaboradores (pais e mães que realizaram adoção) e dois colaboradores que realizaram adoção tardia, os quais participaram da aplicação-piloto para possíveis adequações.

A investigação foi desenvolvida junto ao Setor Técnico de uma Comarca do interior de São Paulo e nas residências dos adotantes que aderiram ao estudo. As pesquisadoras deste estudo, peritas na análise de conteúdo, realizaram suas avaliações via contatos por correio eletrônico (e-mail), por serem de outras universidades e por não residirem na cidade onde foi realizada a pesquisa.

\section{Instrumentos}

Foi elaborado um instrumento (primeira versão) contendo 44 questões, abertas e fechadas, subdivididas em: (1) caracterização dos participantes (itens 1 a 9) em referência a: ambiente familiar (AF) (itens 1, 2, 3, 4 e 9); condições socioeconômicas e culturais (CSEC) (itens 5, 6 e 8) e escolaridade dos adotantes tardios (E) (item 7); (2) adoção tardia e estabelecimento de vínculos afetivos (itens 10 a 40) abordando: adoção e dinâmica familiar (itens 10 a 14); características da criança adotada (itens 15 a 23) e adaptação da criança e estabelecimento de vínculos afetivos (itens 24 a 40); (3) devolução (itens 41 a 44) referente a: aspectos relativos à devolução da criança (para ser respondido somente por casais que realizaram a devolução).

Após a análise teórica - descrita posteriormente na seção Procedimentos - chegou-se a 45 questões abertas e fechadas visando a identificar: (1) caracterização dos participantes (5 questões - ambiente familiar); (2) adoção tardia e estabelecimento de vínculos afetivos (40 questões - dados sobre a adoção e dinâmica familiar, características da criança adotada, adaptação da criança e estabelecimento de vínculos afetivos, relacionamento atual). Foram utilizados como material suplementar: gravador, computador e papel.

\section{Procedimento}

O delineamento do presente estudo comportou duas partes, a análise teórica (parte A) e a aplicação em amostra similar (parte B).

\section{Parte A: análise teórica}

Para contemplar a análise teórica, foram realizadas análise de conteúdo e análise semântica dos itens.

$\mathrm{Na}$ análise de conteúdo, foram consultados nove juízes peritos na área de conhecimento, sendo cinco psicólogos, três assistentes sociais e uma professora doutora na área da adoção que analisou a versão reestruturada, isto é, a versão final. A análise de conteúdo teve como objetivo avaliar a pertinência e relevância dos itens. Os juízes receberam uma versão preliminar do instrumento, contendo instruções específicas para a análise de conteúdo, juntamente com os objetivos do estudo, e uma folha-resposta (protocolo) com a listagem dos itens. Os fatores investigados no estudo foram elencados e dispostos para cada item do instrumento de forma que fosse possível, a cada juiz, identificar e assinalar seu julgamento. Os juízes tiveram liberdade para indicar mais de um fator, caso julgassem que o item pudesse contemplar.

A amostra para a realização da análise semântica foi composta por 11 colaboradores (pais ou mães) que passaram pelo processo de adoção.

A análise semântica consistiu em verificar a clareza de entendimento de cada item constante no instrumento pela amostra estudada e foi realizada com indivíduos pertencentes à população-alvo do estudo em questão (Pasquali, 1996, 2003). Assim, procurou-se uma amostra semelhante à da população-alvo do estudo (pais e mães que passaram pelo processo de adoção) com nível de escolaridade, idade e renda familiar por diferentes categorias e níveis.

Dessa forma, o instrumento na versão preliminar foi aplicado e avaliado com a finalidade de averiguar a necessidade de algum item passar por uma reestruturação ou revisão para propiciar melhor entendimento ou clareza por parte dos colaboradores.

Nesta análise, a pesquisadora optou por aplicar o instrumento em forma de roteiro de entrevista aos onze juízes, que responderam e, ainda, teceram comentários e forneceram sugestões de alterações dos itens/questões. Os dados foram dispostos de forma a apresentar os índices de concordância (IC) entre os juízes, seguindo a apresentação dos tópicos do instrumento e seus itens/questões correspondentes.

Após a realização dos ajustes necessários oriundos da análise teórica (conteúdo e semântica), tomou-se, ainda, um cuidado extra quanto à aferição do instrumento. A versão 
final foi encaminhada para uma perita na área para ser efetuada uma última análise.

\section{Parte B: aplicação em amostra similar}

Finalizada a análise teórica, a etapa seguinte foi a realização de uma aplicação do instrumento, na sua versão final, para últimos ajustes, se necessário. A aplicação aconteceu com duas mães que realizaram adoção tardia, tendo estas, atendido aos critérios (semelhança) da amostra selecionada para o estudo. Para tanto, houve a participação de uma mãe adotante tardia que já possuía filhos biológicos e outra mãe que não possuía filhos biológicos. A aplicação foi programada para ser feita com os casais (pai e mãe), mas durante a aplicação as mães se manifestavam prontamente e se encarregaram de dar as respostas.

\section{Considerações éticas}

A pesquisa foi aprovada pelo Comitê de Ética da Universidade Federal de São Carlos (Protocolo n ${ }^{\circ}$ 224/2006), a participação dos colaboradores foi voluntária e antecedida pela assinatura do Termo de Consentimento Livre e Esclarecido (TCLE).

\section{Resultados}

Os resultados a serem apresentados neste tópico fazem referência às respostas emitidas pelos juízes de conteúdo e juízes de semântica, que dizem respeito à análise teórica do instrumento. A fim de melhor apresentar os resultados, o mesmo foi dividido conforme a sua apresentação na primeira versão. O instrumento utilizado nesta análise correspondeu à primeira versão composta por três partes: (1) caracterização dos participantes (itens 1 a 9); (2) adoção tardia e estabelecimento de vínculos afetivos (itens 10 a 40); (3) devolução (itens 41 a 44).

\section{Caracterização dos participantes (itens 1 a 9)}

De acordo com o retratado na avaliação dos juízes, esses itens corresponderam em sua maioria à finalidade para a qual foram construídos. O conteúdo investigado em cada item pode ser visualizado na Figura 1.
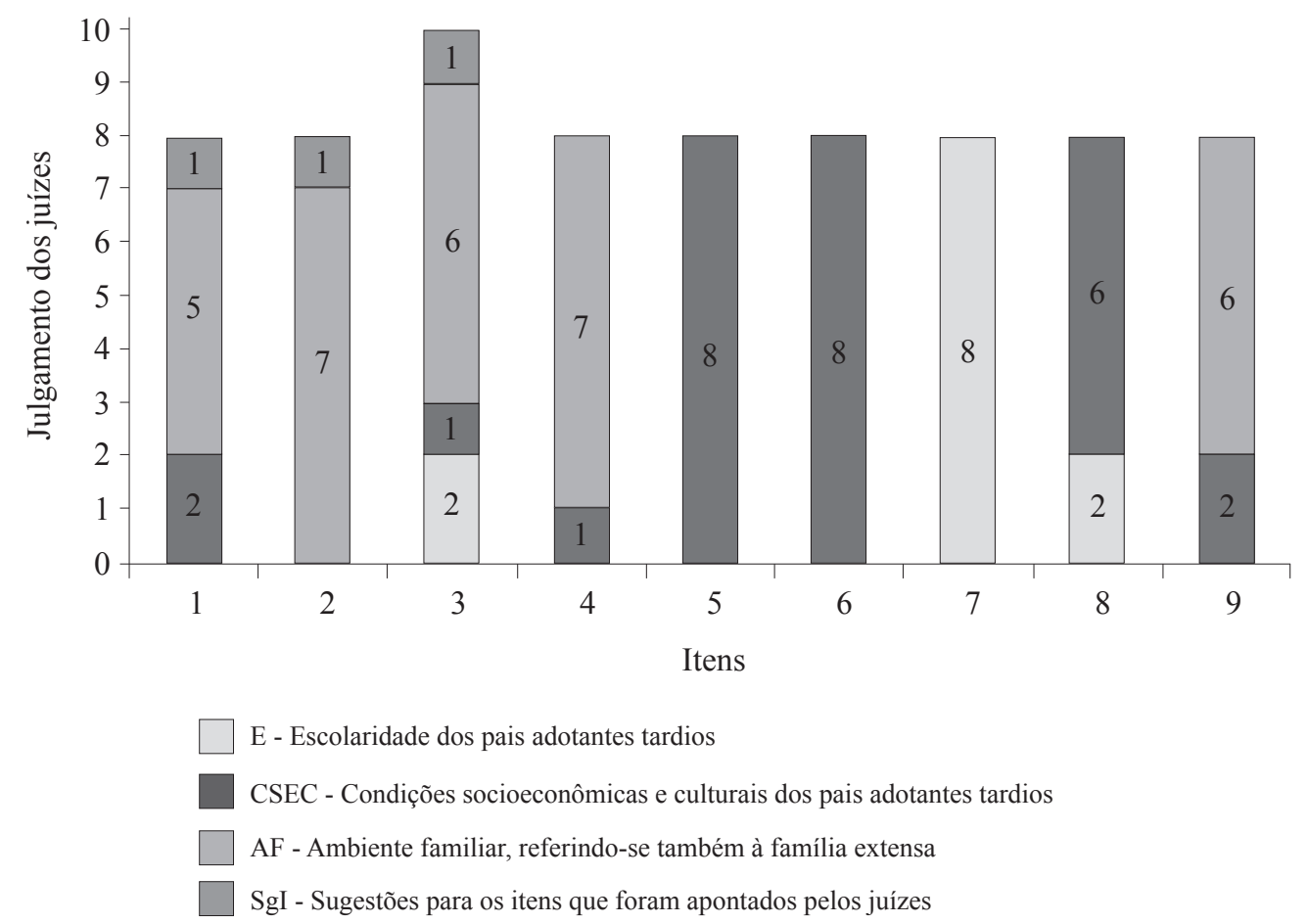

Figura 1. Julgamento dos juízes $(n=8)$ referente ao conteúdo investigado nos itens de caracterização dos participantes.

Dos nove juízes de conteúdo, oito emitiram parecer e pontuaram a adequação e pertinência de cada um dos itens construídos. Somente um dos juízes considerou o instrumento adequado na sua totalidade, fazendo apenas sugestões quanto à sua apresentação e organização. As respostas oriundas da listagem dos itens e associações entre os fatores investigados revelaram que: (a) os itens 5, 6 e 7 tiveram índice de concordância (IC) igual a 100\% em relação ao fator atribuído pelos juízes, o qual foi concordante com o que se pretendeu avaliar ao serem propostos estes itens; (b) os itens $1,2,3,4,8$ e 9 nos julgamentos dos juízes foram associados a mais de um fator (além do proposto pelo item) que poderia 
também ser contemplado pela questão.

As sugestões apresentadas pelos juízes referiram-se à apresentação e organização dos itens (1 a 9) que compuseram a primeira parte do instrumento (caracterização dos participantes). Foi sugerida, pelos juízes de conteúdo, uma junção dos itens (1, 2, 3 e 4), organizando-os em um único quadro, para efeito de uma melhor apresentação, sendo ainda agregadas outras informações como profissão, trabalho atual, nome e ocupação de quem contribui para a renda familiar. Ainda, no item 4, foi sugerido incluir informações sobre os filhos que não residem com os pais no mesmo espaço físico, como grau de escolaridade, idade e local da residência.

Como sugestão para o item 9 apontada por ambos os juízes, de conteúdo e de semântica, foram feitas alterações na questão a fim de tornar mais explícito a qual família se estava referindo, extensa ou de origem. Também foi sugerido, através das análises, que fosse criado um item com informações de apoio/suporte dispensados à família sobre os cuidados domésticos (do lar) e com a criança no momento da inserção da mesma, no período de adaptação. Os itens que não apresentaram consenso entre os juízes sofreram alterações, de acordo com as indicações feitas pelos mesmos, a fim de melhorá-los.

Dessa maneira, conforme ainda pode ser observado na Figura 1, não houve discrepâncias quanto à concordância dos itens, sendo todas as sugestões analisadas e acatadas.

Após essa análise das respostas e elenco de sugestões manifestadas pelos juízes, a parte 1 - Caracterização dos participantes - ambiente familiar (na versão final do instrumento) ficou composta por cinco itens, tornando-os mais abrangentes, de forma que em cada um deles pudessem ser resgatadas informações sobre as condições socioeconômicas, culturais e escolaridade viabilizando, então, retratar, com maior clareza, o ambiente familiar da referida família.
Na análise semântica ( $n=11)$, não houve nenhuma manifestação efetiva por parte dos colaboradores, isto é, nenhuma alteração e/ou sugestão referente aos itens/questões foi indicada. Contudo, as eventuais modificações apresentadas na versão final do instrumento, no que tange à semântica, foram consideradas por entender que as sugestões propostas pelos juízes de conteúdo poderiam favorecer a apresentação e organização visual dos itens, bem como uma melhor construção gramatical das sentenças.

\section{Adoção tardia e estabelecimento de vínculos afetivos (itens 10 a 40)}

Nesta parte do instrumento (adoção tardia e estabelecimento de vínculos afetivos), buscou-se contemplar itens que abrangessem: (a) a adoção e dinâmica familiar (itens 10 a 14); (b) características da criança adotada (itens 15 a 23); (c) adaptação da criança e estabelecimento de vínculos afetivos (itens 24 a 40).

Para essa finalidade, a folha de respostas, entregue aos juízes para efetuarem seus julgamentos, foi composta pela listagem destes itens (na vertical) e fatores para associações (na horizontal), sendo estes: motivação, adoção, características da criança, história de vida da criança, suporte técnico, dificuldades e facilidades e resoluções de conflitos.

\section{Adoção e dinâmica familiar (itens 10 a 14)}

Os itens pertencentes à questão da adoção e dinâmica familiar foram inicialmente propostos para contemplar informações sobre a adoção (itens 10,11 e 12) e dois itens (13 e 14) relacionados à motivação do adotante em relação à inscrição para adoção, idade da criança etc. Conforme pode ser observado na Figura 2, esses itens atingiram o objetivo ao qual foram destinados.

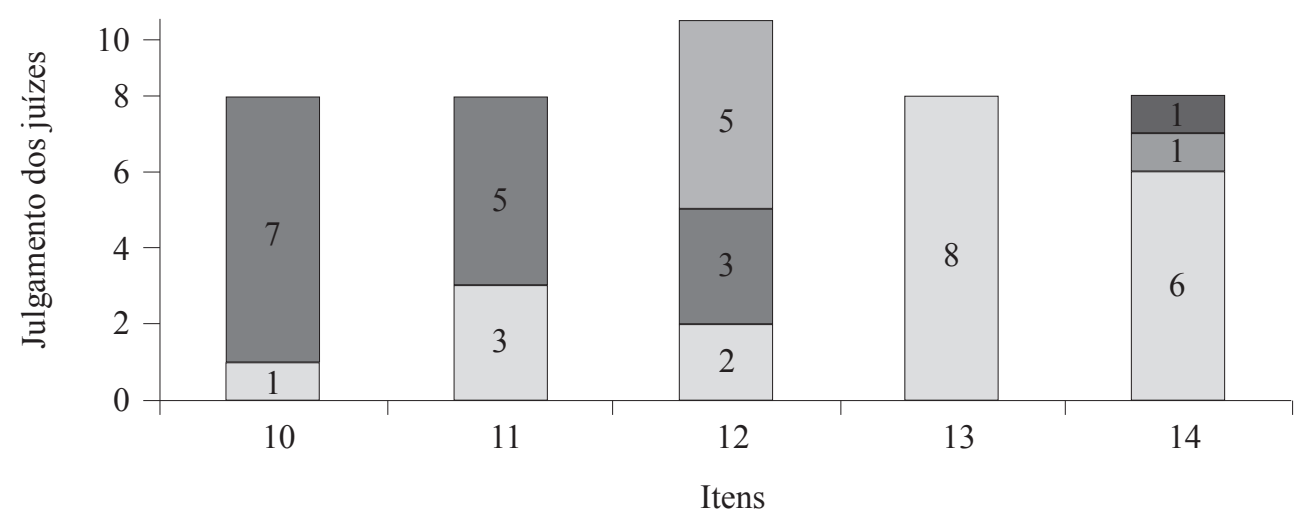

\footnotetext{
M - Motivação dos adotantes tardios para a realização da adoção tardia

A - Aspectos relacionados com a adoção da criança

$\mathrm{CC}$ - Fatores relacionados às características da criança

MA - Mudança de atitude dos pais em relação às características da criança

ST - Suporte técnico prestado aos casais adotantes tardios
}

Figura 2. Julgamento dos juízes referente ao conteúdo investigado nos itens relacionados com aspectos da adoção e dinâmica familiar $(n=8)$. 
Os fatores investigados nessa parte do instrumento (adoção e dinâmica familiar) contemplaram os fatores adoção e motivação, em sua maioria. Portanto, é mister apresentar uma observação oriunda desta análise referente às características da criança. Este fator não fazia parte do quadro de variáveis a serem analisadas por estes itens (10 a 14), mas diante da proximidade aparentemente encontrada entre adoção e características da criança (idade, cor, sexo, etnia), apontada pelos juízes da análise de conteúdo, pode-se inferir que esta associação possivelmente fosse resultado da sua experiência prática que atribui à adoção tardia ainda características especiais, sendo uma delas a idade avançada da criança.

$\mathrm{Na}$ análise semântica, os juízes não evidenciaram nenhuma alteração referente aos itens/questões ou sequer dificuldade de entendimento. No entanto, em decorrência ao fato de não haver nenhuma alteração indicada por eles, o referido item (12) permaneceu como foi inicialmente proposto na versão preliminar do instrumento.

\section{Características da criança adotada (itens 15 a 23)}

No âmbito dos questionamentos sobre as características da criança adotada, estão os itens de 15 a 23.

A análise oriunda dos juízes de conteúdo revelou que as respostas aos itens 15, 16 e 19 foram associadas com o histórico de vida da criança no período anterior à adoção. Os itens 20, 21, 22 e 23 sinalizaram, em sua maioria, as características da criança. Os itens 17 e 18 apontaram predominantemente para as dificuldades e facilidades quanto ao processo de adoção (Figura 3).

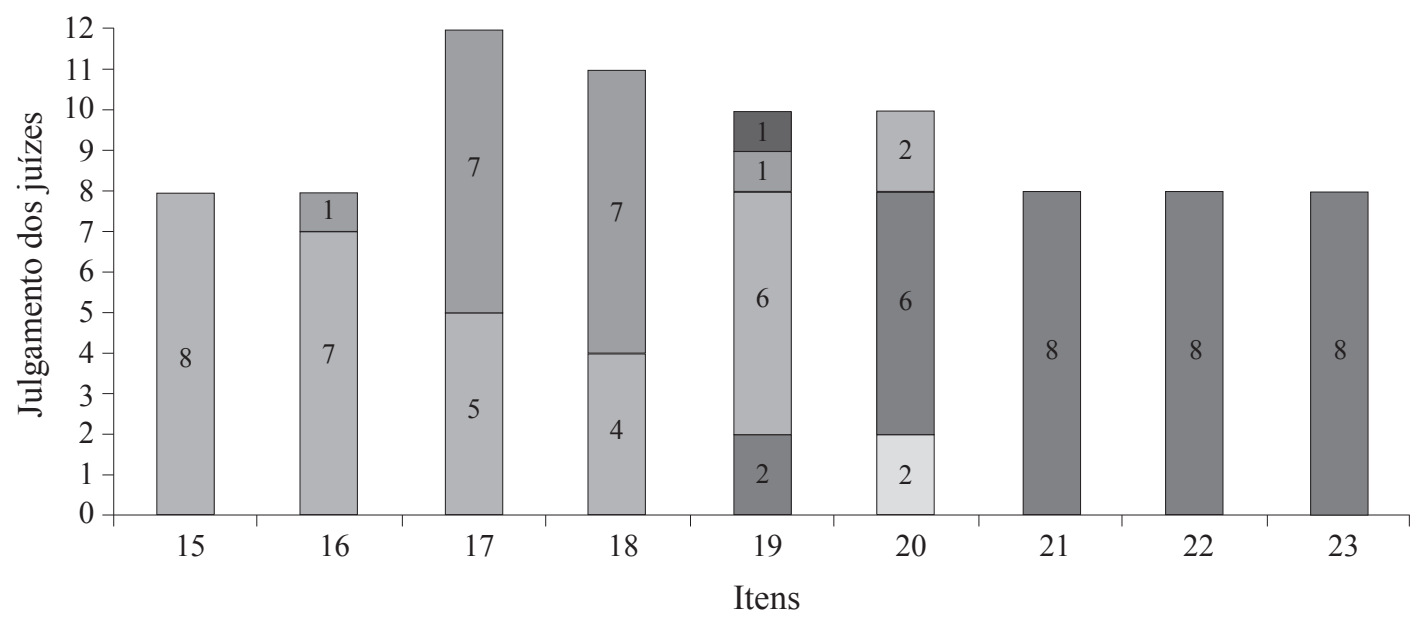

A - Aspectos relacionados com a adoção da criança

$\mathrm{CC}$ - Fatores relacionados às características das crianças

HVC - História de vida da criança adotiva anteriormente ao período de adoção

DF - Dificuldades e facilidades dos adotantes tardios no processo de adoção

RC - Estratégias utilizadas pelos adotantes tardios para a resolução de conflitos

Figura 3. Julgamento dos juízes referente ao conteúdo investigado nos itens relacionados às características da criança adotada $(n=8)$.

Conforme pode ser observado na Figura 3, entre os juízes que emitiram respostas ao procedimento de análise de conteúdo $(n=8)$, o IC foi igual a $100 \%$ para os itens 15 (história de vida da criança) e itens 21,22 e 23 (características da criança). O item 16 apresentou um IC de 87,5\% em relação ao fator evidenciado neste item, sendo este a história de vida e $12,5 \%$ para o fator dificuldades e facilidades.

Os demais itens $(17,18,19$ e 20) foram classificados por eles (juízes de conteúdo) como tendo a possibilidade investigativa de mais de um fator. Contudo, o fator que se propunha investigar nestes itens obteve o maior IC em relação aos outros fatores possíveis de investigação apontados pelos juízes. Os itens 17 e 18, cujo fator de investigação referiase às dificuldades e facilidades no processo de adaptação, apresentaram um IC igual a 58,33\% e 63,64\%, respectivamente. Outro fator sinalizado pelos juízes que poderia ser contemplado por estes dois itens (17 e 18) foi em relação à história de vida da criança, onde se obteve um IC correspondente a $41,67 \%$ e $36,36 \%$, respectivamente. O item 20 revelou um IC em $60 \%$ referente ao fator características das crianças, $20 \%$ para história de vida da criança e $20 \%$ para o fator adoção. 
O item 19, proposto para identificar as dificuldades e facilidades dos pais adotivos e abordando o assunto referente ao receio pela origem da criança, foi identificado, pela maioria dos juízes, como sendo um item relacionado com o fator características das crianças. Sendo assim, este item (19) foi o único que apresentou uma discrepância em relação ao fator investigado que se pretendia analisar (dificuldades e facilidades). Dessa forma, de acordo com o julgamento dos juízes, este item apresentou um IC de $60 \%$ para o fator história de vida da criança. Para os outros fatores indicados por eles, houve um IC de $10 \%$ para dificuldades e facilidades, IC de $20 \%$ para características das crianças e IC de $10 \%$ para resolução de conflitos. Observando atentamente as considerações dos juízes, verificou-se que uma possível ambiguidade na interpretação favorecia e/ou ampliava em potencial $\mathrm{o}$ apontamento do fator receio dos pretendentes à adoção, podendo perceber ainda que este estaria intensamente relacionado à saúde física e emocional das crianças.

Nesse item em especial, mudanças tornaram-se necessárias para tornar a questão mais específica, levando em conta as considerações feitas pelos juízes de conteúdo, pautandose no elenco dos principais receios identificados por eles.

Os resultados advindos da análise semântica convergiram para a necessidade de modificação da estrutura de alguns itens. No caso do item 19, houve a sugestão, por parte dos juízes que efetuaram a análise semântica, de ampliação na categorização dos tipos de receios exemplificados na proposição da questão. Sugestão esta convergente com os dados coletados na análise de conteúdo. Inicialmente (primeira versão do instrumento), o item 19 sinalizava o receio de modo generalizado, isto é, focava mais o aspecto da herança genética da criança. As outras possibilidades e/ou tipos de receios que foram ventilados e que surgiram da análise semântica foram quanto à saúde física da criança, ao uso de bebidas e drogas por parte dos pais biológicos e quanto ao ambiente familiar. Dessa forma, essas quatro categorias e mais uma em aberto designada como "outros fatores" foram inseridas na questão por retratar de maneira ímpar as dificuldades dos pais, podendo estar relacionadas diretamente com a história de vida da criança.

Também foi sugerida uma modificação na ordem de apresentação dos itens $(20,21,22$ e 23), pois, apesar de estes condizerem com os fatores investigados (características da criança), eles remetem a peculiaridades sobre a adoção e o período de adaptação. Dessa forma, as sugestões foram entendidas como relevantes e foram acatadas, transferindo-se o item 20 para a temática da adoção e dinâmica familiar e os demais itens (21, 22 e 23) para a temática da adaptação da criança e estabelecimento de vínculos.

Adaptação da criança e estabelecimento de vínculos afetivos (itens 24 a 40)

No tópico referente à adoção e estabelecimento de vínculos, foi verificada, especificamente nos itens 24 a 40, a adaptação da criança no período de inserção desta junto à família substituta e o estabelecimento de vínculos afetivos decorrentes dessa nova configuração familiar (Figura 4).
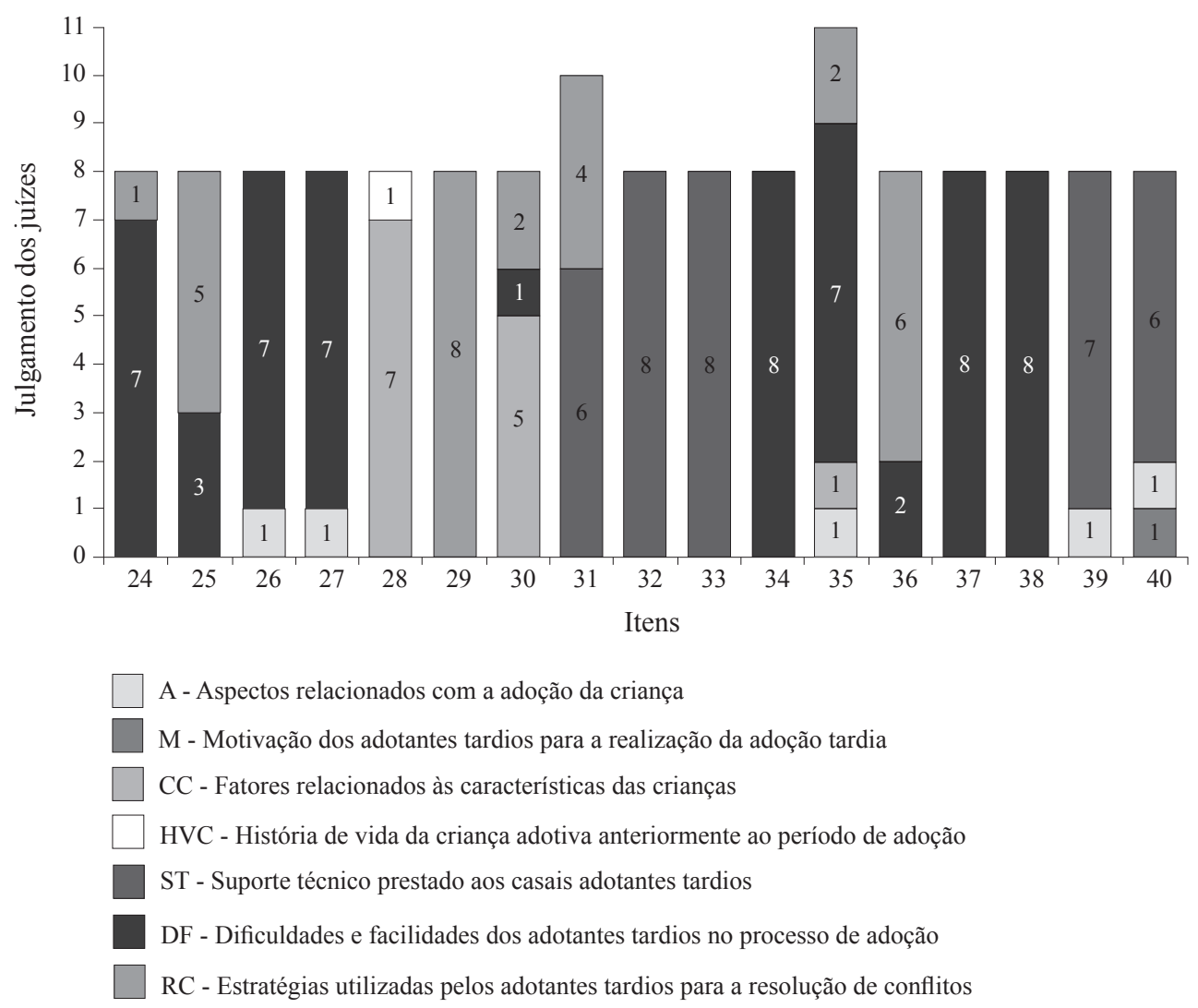

Figura 4. Julgamento dos juízes referente ao conteúdo investigado nos itens relacionados com aspectos da adaptação e estabelecimento de vínculos afetivos $(n=8)$. 
Conforme pode ser observado na Figura 4, os juízes de conteúdo indicaram os fatores investigados pelos itens propostos no instrumento. De acordo com eles, os itens 29 (fator: resolução de conflitos), 32 e 33 (fator: suporte técnico), 34, 37 e 38 (fator: dificuldades e facilidades) avaliam o que se propõe, pois estes itens obtiveram IC de $100 \%$ no julgamento destes.

Os itens 24, 26 e 27 apresentaram, por meio da análise dos juízes de conteúdo ( $\mathrm{n}=8)$, uma concordância mais elevada (acima de 85\%) para o fator que estes itens estariam avaliando, ou seja, com a finalidade para a qual foram criados fator dificuldades e facilidades.

Os itens 25 e 36 apresentaram um IC maior em correspondência ao fator investigado pelos itens (fator: resolução de conflitos), não havendo discrepância entre a versão do instrumento proposta inicialmente.

Ainda baseando-se na Figura 4, os dados oriundos desta análise de conteúdo evidenciaram que os itens 31 e 35 foram classificados pelos juízes como compostos por mais de um fator, contudo, houve concordância predominante entre os fatores investigados na versão preliminar do referido formulário de pesquisa. Dessa maneira, o item 31, apesar de obter $60 \%$ IC ao fator investigado proposto (suporte técnico) apresentou, também, IC de $40 \%$ para resolução de conflitos. Semelhança pôde ser encontrada no item 35 que apresentando IC de $63,64 \%$ para o fator dificuldades e facilidades adicionalmente teve IC de 18,18\% para o fator resolução de conflitos, 9,09\% para características das crianças e 9,09\% para o fator adoção.
No entanto, convém evidenciar que o item 35 referese às dificuldades da criança e ao enfrentamento no âmbito escolar. De acordo com os resultados, pôde-se verificar que houve em algumas respostas dos juízes uma inter-relação com os fatores referentes à adoção, características da criança e resolução de conflitos.

\section{Devolução (itens 41 a 44)}

Esta parte do instrumento de pesquisa mencionou os aspectos relativos à devolução da criança (para ser respondido somente por casais que realizaram a devolução).

Pautando-se nas respostas dos juízes expostas na Figura 5 , foi possível verificar que os itens referentes à devolução envolveram ou correlacionaram fatores motivacionais com IC de 75,50\%, 12,50\% referente ao fator estágio de convivência e $1,50 \%$ devido às características das crianças (item 41). No item 42 um número expressivo de juízes apontou para variáveis referentes ao estágio de convivência com IC de $75,50 \% ; 12,50 \%$ para o fator motivação e $12,50 \%$ para as características das crianças como aspectos envolvidos na investigação propiciada por este item.

As características da criança foram fator constituinte dos itens 43 e 44, sendo o julgamento dos juízes relativo à IC igual a 50\% em ambos os itens. O item 43 ainda comportou um IC de $25 \%$ para o fator motivação. Índices semelhantes puderam ser observados no item 44, onde o IC foi de $25 \%$ para a variável motivação e a porcentagem restante $(25 \%)$ correspondeu à quantidade de ausência de respostas ao item.

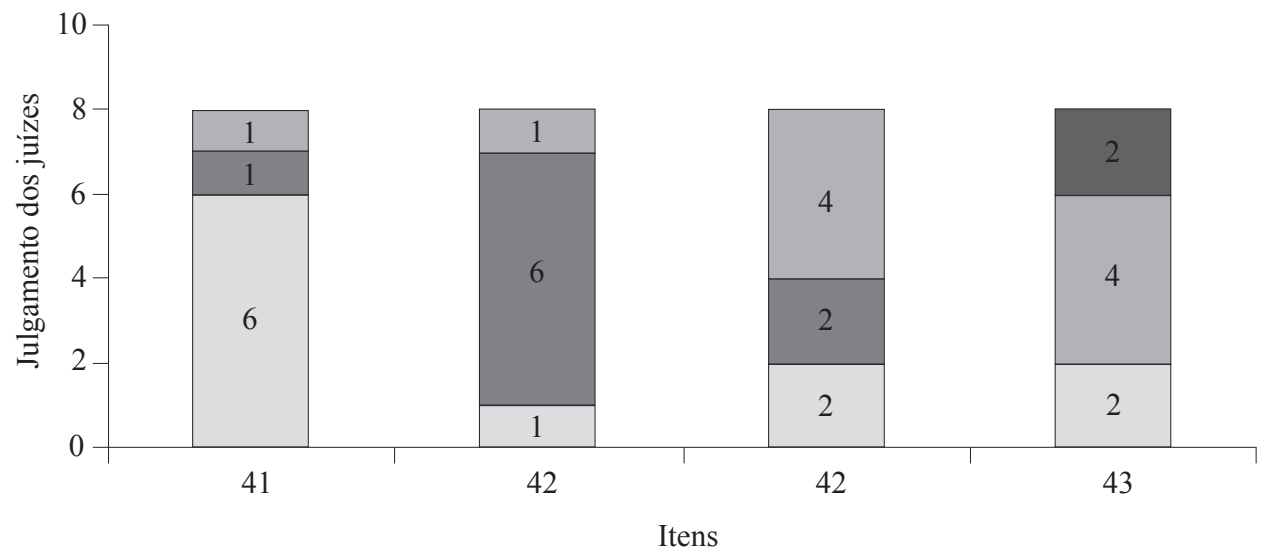

\footnotetext{
M - Motivação dos adotantes tardios para a realização da adoção tardia

EC - Estágio de convivência com os casais pretendentes à adoção tardia

$\mathrm{CC}$ - Fatores relacionados às características das crianças

NR - Não respondeu ao item
}

Figura 5. Julgamento dos juízes $(n=8)$ referente ao conteúdo investigado nos itens relacionados à devolução das crianças no período de guarda. 
Por sugestão, essas questões finais foram alteradas (agrupadas) e incorporadas aos demais itens no tópico anterior. Assim, o tópico 3 (Devolução) deixou de ser considerado como um tópico específico. Coincidentemente, esta consideração também foi apontada na análise semântica.

Após essa etapa de condução da análise de conteúdo e semântica, o instrumento foi aperfeiçoado, sendo feita uma reestruturação dos itens inicialmente propostos. Dessa forma, o instrumento na versão reestruturada passou a apresentar somente dois tópicos: (1) Caracterização dos participantes (05 itens) e (2) Adoção tardia e estabelecimento de vínculos afetivos (40 itens). Para se obter um melhor controle na aferição do instrumento, isto é, sua qualidade psicométrica, o conteúdo reestruturado foi submetido à análise de uma especialista (pesquisadora) na área de adoção. Frente aos comentários desta última juíza de conteúdo, o instrumento foi considerado como adequado para aplicação, sendo, portanto, garantida a validade de conteúdo.

Com essa aferição e a certeza de que o instrumento já poderia ser utilizado, passou-se para a etapa final que consistiu em uma aplicação-piloto para a testagem do instrumento e treino do aplicador, podendo ser avaliados o tempo de administração (média de 50 minutos) e a forma de registro e gravação das entrevistas.

Para essa etapa, o instrumento foi aplicado em duas mães que foram selecionadas de acordo com o perfil da amostra, pois realizaram adoções tardias. Havia planejamento de entrevistar também os pais, mas os mesmos justificaram que devido ao acúmulo de serviços optavam por não fazer a entrevista. De maneira geral, na aplicação do instrumento não foi observada e/ou manifestada dificuldade de entendimento ou compreensão dos itens por parte das colaboradoras.

\section{Discussão}

Em atendimento à necessidade social e prática satisfatória visando à intervenção e orientação de pais pretendentes à adoção, este trabalho ancorou seus objetivos. Posto isto, primou-se pela construção de um instrumento para a obtenção de informações sistematizadas na prática da adoção tardia e que pudesse ter uma utilização versátil (como: questionário, formulário ou entrevista) em função da interação bipessoal possível com os atores envolvidos. Nesse cenário, onde prevalece a necessidade de uma prática consciente e efetiva, resultados que apontem para as dificuldades e facilidades dos pais que efetivaram adoções tardias diante da vinculação afetiva são requeridos a fim de possibilitar futuras intervenções e práticas.

A equipe de profissionais que atua no processo de adoção, o referido suporte técnico, conforme apontado por Ambrósio, Pontes, Cabrera e Aiello-Vaisberg (2006), deve estar atenta ao histórico de vida da criança, sendo imprescindível averiguar sobre as possíveis perturbações e quanto ao grau destas, realizando dessa maneira um prognóstico de cada caso para que a atuação seja efetiva, assim como o encaminhamento, inserção e adaptação desta a um novo ambiente familiar.

Sendo assim, a partir da aplicação de procedimentos científicos e técnicas psicométricas, foi possível obter um instrumento, por meio do qual informações objetivas e válidas sobre vários questionamentos referentes à adoção, mais especificamente a tardia, poderão ser viabilizadas. Ao serem gerados esses dados informativos, avança-se no sentido de possibilitar que ações interventivas e atuações no âmbito da orientação junto às famílias adotantes possam ser sistematizadas e aplicadas. Seguimentos técnicos do setor judiciário, bem como os grupos de apoio à adoção, poderão lançar mão deste recurso técnico a fim de sustentar uma prática adequada e satisfatória na condução do processo de adoção.

Frente ao processo de validação do instrumento, deparou-se com alguns aspectos que merecem ser discutidos. Dentre eles podem ser apontadas as tendências interpretativas por parte dos colaboradores e a administração individual do formulário.

A necessidade da forma de aplicação ser realizada de maneira individualizada, ou seja, com o pai e com a mãe separadamente, foi inicialmente sinalizada na análise semântica. Este aspecto foi reforçado na aplicação da versão reestruturada (final) na testagem-piloto do instrumento. A opção por esta forma de administração buscou identificar a visão dos pais diante da prática efetiva no processo de adoção, suas responsabilidades e atribuições de tarefas. Morelli (2005) apontou em seu estudo que, na opinião dos pais, a responsabilidade pela educação e pelos cuidados diários ficam sob a vigência das mães. De acordo com eles, na referida pesquisa, aos pais $(50 \%)$ cabem os cuidados financeiros, sendo o restante $(50 \%)$ dividido com o seu cônjuge. No caso específico deste estudo, percebeu-se que, ao delegarem as respostas ao formulário para as mães e manifestarem preferência por não responderem às questões, os pais tendem a refletir o comportamento descrito no trabalho de Morelli.

Ao abordar os aspectos do processo de construção do instrumento, constatou-se que os itens obtiveram índices de concordância (IC) adequados ( Acima de 80\%), em relação ao fator avaliado pelo item, conseguidos a partir das avaliações dos juízes de conteúdo e semântica. Há exemplo de alguns itens que foram interpretados como abrangendo mais de um fator e, mesmo assim, o IC para o fator que o item propunha avaliar foi o maior dentre as outras possibilidades indicadas. Houve um item proposto, o item 12, inicialmente abordando conceitos sobre a adoção e dinâmica familiar, retratado na análise dos juízes como adequado para a obtenção de informações referentes às características das crianças. Observou-se, dessa maneira, o quanto a imagem de adoção e, em evidência, a adoção tardia, pode estar vinculada às características físicas da criança. Esses resultados decorrem do que ainda se observa na prática, ou seja, uma busca inserida nos desejos e interesses particulares em detrimento das necessidades da criança (Freire, 2001; Vargas, 1998; Weber, 1999, 2001). Em função desse viés de julgamento observado, 
o item não sofreu alteração na versão reestruturada (final), uma vez que a sua identificação com o fator características da criança provavelmente refletiu a discrepância subjetiva encontrada neste item.

Focando a questão de número 19, pôde-se observar que o conceito "receio" permeia o processo de adoção. Os resultados obtidos deram indícios dos tipos de receios, os quais estariam diretamente correlacionados com a saúde física e emocional da criança, o uso de bebidas e drogas consumidas pelos pais biológicos e o ambiente familiar. Apreende-se que os receios elencados, pelos participantes, parecem interferir na prática da efetivação de uma adoção tardia. Há ainda que se constatar que pouco ou quase nada se fala na adoção de crianças com necessidades especiais.

Ao ser abordado o fator história de vida da criança, foi possível refletir o quanto as dificuldades e facilidades encontradas no processo de adaptação familiar, isto é, no período de convivência, estão enraizadas e associadas às características da criança e histórico de vida ou nas atitudes comportamentais das mesmas.

As tendências das respostas obtidas nas análises dos itens que envolvem esta questão coincidem com a explanação feita por Coakley e Berrick (2008), quando estes apontam para as características das crianças que estão associadas aos fatores que contribuem para o rompimento da adoção. Dentre elas estariam: o gênero da criança, a idade, o vínculo afetivo, grupo de irmãos, duração dos cuidados para com a criança e as necessidades especiais. Os autores ainda incluem as necessidades emocionais, cognitivas e comportamentais, mostrando que as pesquisas apontam para a inclusão, entre as necessidades especiais, o histórico de abuso e a exposição desde o período gestacional ao abuso de substâncias.

No entanto, Coakley e Berrick (2008), ao apontar aspectos desses rompimentos, recomendam uma definição comum para o rompimento da adoção, sendo que esta ajudaria as diversas linhas de pesquisa a encontrarem resultados significativos. Recomendam a utilização do termo "rompimento pré-finalizado" quando decorre antes de finalizada a adoção legalmente e "rompimento da adoção" apenas para casos em que a adoção legal foi concretizada.

As conclusões sobre as implicações práticas e políticas vinculadas ao rompimento na adoção, de acordo com Coakley e Berrick (2008), podem ser generalizadas para outros países, na medida em que sejam verificadas as características associadas ao rompimento na adoção. Há concordância com os autores quando apontam para a necessidade de novos estudos que resultem na redução de rompimentos na adoção, ampliando a colocação de crianças e a sua real permanência nas famílias adotivas.

No tocante às dificuldades enfrentadas no âmbito escolar, os resultados das análises evidenciaram que os fatores adoção e características das crianças se relacionam, exemplo deste aspecto pode ser identificado com o IC referente ao item 35 (Seu(a) filho(a) enfrentou ou enfrenta dificuldades no âmbito escolar por ser adotivo(a)?) que apesar da obtenção de um IC identificado com a proposta inicial da construção do item, os juízes sinalizaram a associação de outros fatores que supostamente poderiam ser investigados, como: (a) resolução de conflitos; (b) características das crianças e adoção. De acordo com Miall (1996), os pais adotivos tendem a exigir um perfeccionismo dos seus filhos, principalmente no âmbito acadêmico, mantendo dessa forma altas expectativas sobre a sua realização.

Diante dessa cultura da adoção tão amplamente difundida por Freire (2001), onde se busca uma família para uma criança e não a satisfação e bem-estar da família em primeiro lugar, um questionamento bastante evidenciado e contemplado pela literatura faz referência às características físicas das crianças eleitas como preferidas na procura da adoção (Vargas, 1998; Weber, 1999, 2001). As crianças de menor idade, brancas, saudáveis e de preferência meninas são as preferidas para a inserção imediata em famílias substitutas (Beffa \& Pocay, 1999; Camargo, 2005; Cassin, 2000; Hamad, 2002; Maldonado, 1995; Paiva, 2004; S.S.M. Schettini, 2007; Vargas, 1998; Weber, 2001). Mesmo referenciando a idade avançada da criança como possível causa para os conflitos e os fatores estressores dos pais adotivos, Bird e cols. (2002) também evidenciaram, pela análise de seus resultados, que os pais apresentaram estratégias focadas no coping, um maior senso de planejamento, necessitando dessa forma de menor suporte para os membros da família.

\section{Considerações finais}

Os resultados do presente estudo evidenciaram que, durante a adaptação da criança e o estabelecimento de vínculos afetivos na adoção tardia, o suporte técnico oferecido às famílias esteve relacionado de maneira muito próxima à resolução de conflitos, na medida em que puderam fornecer orientações e apoio às famílias.

No entanto, buscar estratégias que ressaltem as maneiras de como solucionar os conflitos ou orientações quanto a sua prevenção também precisa ser apontado de maneira mais sistematizada. Os resultados encontrados, através da análise semântica, revelaram possibilidades profícuas para elencálas, levando em consideração a idade da criança. Ainda, o instrumento proposto neste estudo favorece a avaliação da adequação das estratégias utilizadas pelos pais ao correlacioná-las com as características da criança e sua idade.

Nesse sentido, alternativas para a mudança na cultura da adoção também poderão ser proporcionadas pelo referido instrumento, sendo um material rico para desencadear discussões e ações que primam por mudança na cultura da adoção. Além de seu caráter interventivo e de orientação de pais tardios (no processo de adoção tardia), será capaz de mobilizar discussões sobre a cultura da adoção e viabilizar reflexões e mudanças acerca do tema. 


\section{Referências}

Ambrósio, F. F., Pontes, M. L. S., Cabrera, J. C., \& AielloVaisberg, T. M. J. (2006). Como o psicanalista pode contribuir no processo de adoção: Reflexões sobre a investigação do imaginário de um grupo de professoras sobre uma criança adotada. In T. M. J. A. Aiello-Vaisberg (Org.), Cadernos ser e fazer: Imaginários coletivos como mundos transacionais (pp. 46-60). São Paulo: Instituto de Psicologia/Universidade de São Paulo.

Andrei, D. C. (1999). Adoção tardia. In D. C. Andrei (Org.), Reencontro com a esperança: Reflexões sobre a adoção e a familia (pp. 89-101). Londrina, PR: M\&C.

Beffa, A. R., \& Pocay, M. C. H. (1999). Adoção tardia: A possibilidade da modernidade. In D. C. Andrei (Org.), Reencontro com a esperança: Reflexões sobre a adoção e a família (pp. 33-41). Londrina, PR: M\&C.

Bird, G. W., Peterson, R., \& Miller, S. H. (2002). Factors associated with distress among support-seeking adoptive parents. Family Relations, 51(3), 215-220.

Camargo, M. L. (2005). Adoção tardia: Representações sociais de famílias adotivas e postulantes à adoção mitos, medos e expectativas. Dissertação de mestrado não publicada, Faculdade de Ciências e Letras de Assis, Universidade Estadual Paulista, Assis, SP.

Camargo, M. L. (2006). Adoção tardia: Mitos, medos e expectativas. Bauru, SP: EDUSC.

Cassin, W. C. (2000). O psicólogo judiciário e a cultura da adoção: Limites, contradições e perspectivas. Dissertação de mestrado não publicada, Faculdade de Filosofia, Ciências e Letras de Ribeirão Preto, Universidade de São Paulo, Ribeirão Preto, SP.

Coakley, J. F., \& Berrick, J. D. (2008). Research review: In a rush to permanency: Preventing adoption disruption. Child and Family Social Work, 13(1), 101-112.

Costa, N. R. A. (2005). Construção e sentidos relacionados à maternidade e à paternidade em uma família adotiva. Tese de doutorado não publicada, Faculdade de Filosofia, Ciências e Letras de Ribeirão Preto, Universidade de São Paulo, Ribeirão Preto, SP.

Ebrahim, S. G. (1999). Adoção tardia: Altruísmo, maturidade e estabilidade emocional. Dissertação de mestrado não publicada, Universidade Federal da Paraíba, João Pessoa.

Freire, F. (2001). Abandono e adoção: Contribuições para uma cultura da adoção. Curitiba: Terra dos Homens.

Hamad, N. (2002). A criança adotiva e suas famílias (S. R. Felgueiras, Trad.). Rio de Janeiro: Cia. de Freud.

Kossobudzki, L. H. M. (1999). Adoção tardia. In D. C. Andrei (Org.), Reencontro com a esperança: Coletâneareflexões sobre a adoção e a família (pp. 39-41). Londrina, PR: M\&C.

Lei No. 8.069, de 13 de julho de 1990. (1990, 16 de julho). Dispõe sobre o Estatuto da Criança e do Adolescente e dá outras providências. Diário Oficial da União, seção 1.
Levinzon, G. K. (2004). Adoção. São Paulo: Casa do Psicólogo.

Levy-Shiff, R. (2001). Psychological adjustment of adoptees in adulthood: Family environment and adoptionrelated correlates. International Journal of Behavioral Development, 25(2), 97-104.

Maldonado, M. T. (1995). Os caminhos do coração: Pais e filhos adotivos. São Paulo: Saraiva.

Mariano, F. N., \& Rosseti-Ferreira, M. C. (2008). Que perfil da família biológica e adotante, e da criança adotada revelam os processos judiciais? [Versão eletrônica]. Psicologia: Reflexão e Crítica, 21(1), 11-19. Recuperado em 02 dezembro 2008, de http://www.scielo.br/pdf/prc/ v21n1/a02v21n1.pdf

Miall, C. E. (1996). The social construction of adoption: Clinical and community perspectives. Family Relations, 45(3), 309-317.

Morelli, R. (2005). Análise do convívio de pais e filhos adotivos. Monografia não publicada, Universidade Federal de São Carlos, São Carlos, SP.

Paiva, L. D. (2004). Adoção: Significados e possibilidades. São Paulo: Casa do Psicólogo.

Pasquali, L. (Org.). (1996). Teorias e métodos de medida em ciências do comportamento. Brasília, DF: UnB/INEP.

Pasquali, L. (2003). Psicometria: Teoria dos testes na psicologia e na educação. Petrópolis, RJ: Vozes.

Richardson, R. J. (1999) Pesquisa social: Métodos e técnicas (3a ed.). São Paulo: Atlas.

Schettini, L. (1998). Compreendendo os pais adotivos. Recife: Bagaço.

Schettini, L. (2006). Uma psicologia da adoção. In L. Schettini \& S. S. M. Schettini (Orgs.), Adoção: Os vários lados dessa história (pp. 99-120). Recife: Bagaço.

Schettini, S. S. M. (2007). Filhos por adoção: Um estudo sobre o seu processo educativo em famílias com e sem filhos biológicos. Dissertação de mestrado não publicada, Universidade Católica de Pernambuco, Recife, PE.

Souza, H. P. (2003). Adoção é doação. Curitiba: Juruá.

Vargas, M. M. (1998). Adoção tardia: Da família sonhada à família possível. São Paulo: Casa do Psicólogo.

Vargas, M. M. (2006). Adoção de crianças maiores. In L. Schettini \& S. S. M. Schettini (Orgs.), Adoção: Os vários lados dessa história (pp. 147-171). Recife: Bagaço.

Viana, A. B. (2000). Relato de profissionais a respeito dos motivos que levam à devolução de crianças colocadas em família substituta. Monografia não publicada, Universidade Federal de São Carlos, São Carlos, SP.

Weber, L. N. D. (1999). Laços de ternura: Pesquisas e histórias de adoção (2a ed.). Curitiba: Juruá.

Weber, L. N. D. (2001). Pais e filhos por adoção no Brasil: Características, expectativas e sentimentos. Curitiba: Juruá.

Weber, L. N. D. (2003). Aspectos psicológicos da adoção (2a ed.). Curitiba: Juruá. 
Katia Cristina Bandeira Dugnani é Mestre em Educação Especial pelo Programa de Pós-graduação em Educação Especial da Universidade Federal de São Carlos.

Susi Lippi Marques é Professora Associada da Universidade Federal de São Carlos.

Recebido: $13 / 01 / 2010$

$1^{a}$ revisão: $15 / 04 / 2010$

$2^{a}$ revisão: $19 / 07 / 2010$

Aceite final: 10/03/2011 